\title{
Cancillería castellana y lengua vernácula. Su proceso de consolidación
}

\author{
Pilar Ostos Salcedo \\ Universidad de Sevilla
}

RESUMEN ABSTRACT

La utilización de la lengua romance en la cancillería regia castellana fue resultado de un paulatino proceso que puede rastrearse a través de los numerosos documentos conservados y en los que se aprecia cómo se fue imponiendo al latín en función del contenido de los documentos y de su tipología. Los primeros indicios claros se detectan en la última etapa del reinado de Alfonso VIII, es decir, a finales del siglo xll y primeros años de la centuria siguiente. Su avance es incontestable en la época de Fernando III y en especial a partir de 1230. El triunfo del castellano en la documentación real también notarial-se produce en la segunda mitad del siglo XIII, en el decisivo reinado de Alfonso $X$.

\section{PALABRAS CLAVE}

Diplomática, Cancillería, Castellano.
The use of the Romance language in the Castilian royal Chancellory was the result of a progressive process tracked through many documents preserved, and in which it is observed how it was imposing to the latin, according to the documents contents and their typology. The first clear signs are detected during the last years of the kingdom of Alphonse VII, that is to say, at the end of the $12^{\text {th }}$ century, and during the first years of the following century. Its advance is unquestionable during Ferdinand III, and specially since 1230. The success of the Castilian language in the royal documentation - also in the notarial- happens in the second half of the $13^{\text {th }}$ century, during the decisive kingdom of Alphonse $X$.

\section{KEY WORDS}

Diplomatics, Chancellory, Castilian.

Lengua materna, lengua vulgar, plano lenguaje o ya castellano son diferentes términos de la época para designar una realidad lingüistica que, de manera inexcusable, pasó de la oralidad a la escritura a lo largo de un proceso relativamente lento que triunfó definitivamente en Castilla con el decisivo reinado de Alfonso X (1252-1284). 
Dada la enorme trascendencia de este tema, como es lógico numerosos especialistas en Historia de la Lengua han dedicado sus investigaciones a determinar el inicio del castellano, su proceso de transformación y su definitiva consolidación. Desde el ya clásico trabajo de R. Menéndez Pidal sobre los documentos lingüísticos de España ${ }^{1}$ a los más recientes estudios realizados por $\mathrm{R}$. Wright acerca del primer romance ${ }^{2}$ y que tanta repercusión han tenido en este campo. Entre otros muchos.

En la mayoria se pone de manifiesto la disociación existente en esos siglos medievales entre lengua hablada y lengua escrita, hasta que la primera comenzó a ser trasladada también al plano de la escritura. Fue una época larga - que algunos localizan desde fechas muy tempranas-, en la que el latín sobrevivió como lengua del Derecho, de las cancillerías y, en especial, de la Iglesia. Una época en la que esa unidad lingüística europea se mantenía en el campo de la escritura, pero cada vez menos en el de la conversación, pues paulatinamente se fueron conformando las distintas lenguas romances, que con el tiempo -pero también poco a poco- pasaron a ser fijadas por escrito. El latín, por tanto, era la lengua de las personas doctas y la utilizada en público para las manifestaciones solemnes.

En la corona castellana, el paso del romance a los textos hay que situarlo con claridad en la primera mitad del s. XIII. No obstante, ya en documentos reales del siglo anterior se observan palabras -en especial alusivas a topónimos- con un fuerte carácter romanceado, amén de otras tomadas prestadas del árabe. Muchos estaban escritos en un latín vulgar asimilado a la fonética romance, en el que vocablos romances aparecían latinizados y otros se romanceaban, dando lugar a una enorme mezcla de formas latinas y romances ${ }^{3}$.

En el ámbito notarial, señala R. J. Blake que se hace muy común encontrar textos notariales de los siglos X\| y XIII que comienzan y terminan con fórmulas latinas, mientras que el texto aparece en una incipiente ortografía romanceada o en un latín muy evolucionado ${ }^{4}$. Esta realidad es apreciable de igual manera en la documentación emitida por la oficina de expedición de los reyes castellanos, en un proceso que A. Emiliano considera de “Cadena ininterrumpida de romanización" ${ }^{5}$.

I. Párrafos completos o determinadas fórmulas en castellano se empiezan a encontrar en los albores de la decimotercera centuria. Más concretamente, en ciertos documentos del largo, intenso e interesante reinado de Alfonso VIII (1158-

Vid. R. Menéndez Pidal, Documentos lingüisticos de España I. Reino de Castilla, Madrid, 1966. reimpr.

Vid. R. WRIGHT, Late Latin and Early Romance in Spain and Carolingian France, Liverpool, 1982. Traducción española: Latín tardio y romance temprano, Madrid, 1988.

Vid. I. ARANZABE Férez, "Textos romances e interpretación", en Actas / Congreso Nacional de Latin Medieval, León, 1995.

4Vid. R. J. BlAKE, "El latin notarial de un escriba bilingüe o digrafo del Xil", en Actas I Congreso Nacional de Latín Medieval, León, 1995, p. 463.

${ }^{5} \mathrm{Vid}$. A. EmILiANO, "Tradicionalidad y exigencias de realismo en la lengua notarial hispánica", en ACtas I Congreso Nacional de Latín Medieval, León, 1995, p. 511. 
1214) ${ }^{6}$. De latín medieval cancilleresco - y más culto que el utilizado con anterioridad - califica M. Pérez González el que presentan los numerosos documentos producidos por su cancillería, si bien la influencia del romance se hizo cada vez mayor?.

De los novecientos ochenta y cinco de este monarca publicados por J. González $^{8}, \mathrm{D}$. W. Lomax determina que se conservan en vernáculo tres originales, ya del siglo XIII - 1206, 1210 y $1213^{\circ}$ - a los que habría que sumar otros siete que sin embargo han llegado a través de copias posteriores. Su grado de transmisión lleva a este estudioso a no considerarlos como fuentes fidedignas, ya que podrían tratarse - según él-de traducciones posteriores ${ }^{10}$. Disiente L. Rubio García de esta selección de documentos y prescinde del tercer original analizado por el anterior, pues se conserva inserto en una confirmación de Sancho IV ${ }^{11}$. A su vez, este último incorpora otros tres diferentes, que se han transmitido copiados en sendos cartularios coetáneos ${ }^{12}$, así como dos pesquisas ${ }^{13}$, aún reconociendo este autor que ambas no son propiamente documentos de la cancilleria regia ${ }^{14}$. Veamos más detenidamente los textos seleccionados por ambos especialistas.

Uno de los tres supuestos originales destacados por Lomax es considerado por su editor - J. González-como copia imitativa de la época ${ }^{15}$. Por tanto, de esa terna quedaria al final sólo uno, que es precisamente el más antiguo y el que contiene el célebre tratado de Cabreros acordado - en 1206- entre los monarcas de Castilla y de León ${ }^{16}$. Se trata de un privilegio rodado, con doble signo inserto en rueda - uno de cada rey- escrito el ejemplar para el monarca leonés por su notario Petrus Petri y por mandato del canciller Fernando, deán de Compostela ${ }^{17}$, y el del rey castellano por el notario Dominicus tras iussio del canciller Diego Garcia ${ }^{18}$. Ambos diplomas aparecen íntegramente escritos en castellano, excepto una breve invocación al nombre de Cristo, la data y las cuatro columnas de confirmantes --dos de cada reino-. Llama la atención que sea precisamente éste el primer documento cancilleresco original escrito casi totalmente en romance, pues se trata de un pacto entre ambos reinos para determinar las villas y castillos que Alfonso VIII y Alfonso IX concedian a su respectivo nieto e hijo - -el futuro Fernando III-

Vid. J. Gonzalez, El reino de Castilla en la época de Alfonso VIII, Madrid, 1960.

Vid. M. Pérez Gonzalez, El latín de la cancilleria castellana (1158-1214), Salamanca-León, 1985 , pp. 251-255.

8 Vid. J. Gonzalez, Op. cit., t. II y III.

Ibidem, docs. 782, 905 y 1031.

10 Vid. D. W. Lomax, "La lengua oficial de Castilla", en Actele celui de-al Xll-lea Congres Internacional de Linguistica si filologie Romanica, Bucarest, p. 412.

11 Vid. J. GONZALEZ, dOc. 1031.

12. Ibidem, docs. 632 y 889. R. Menendez Pidal, Op. cit, doc. 4.

13 J. Gonzalez, Op. cit., doc. 905. R. Menendez Pidal, Op. cit., doc. 165.

14 Vid. L. RuBio Garcia, Del latín al castellano en las escrituras reales, Murcia, 1981, pp. 9-11.

15 Vid. J. GONZAlez, Op. cit., doc. 905.

5 Ibidem, doc. 782.

Vid. M. Lucas Álvarez, Las cancillerias reales (1109-1230), León, 1993, pp. 515-516 y 521.

16 Vid. P. Ostos SALCEDo, "La cancillería de Alfonso VIII, rey de Castilla (1158-1214). Una aproximación", en Boletin Millares Carlo, 13 (Las Palmas de Gran Canaria, 1994), pp. 112-113. 
amén de ciertos acuerdos relacionados con la dote de $\mathrm{D}^{\mathrm{a}}$ Berenguela, madre del citado Fernando. Otros tratados entre ambos reinos y posteriores en el tiempo, como el de Valladolid de $1209^{19}$, el de Toro en $1216^{20}$ y una tregua en $1217^{21}$, fueron escritos íntegramente en latín. Justifica J. M. ${ }^{a}$ Fernández Catón su uso con el hecho de que su redacción recaería en la cancillería castellana y, asimismo, por la preponderancia de Alfonso VIII sobre su homónimo, al que al parecer tenía sometido ${ }^{22}$. Sin tener elementos de juicio para cuestionar su originalidad, aceptada por otra parte por los diferentes estudiosos que se han acercado a este importante tratado, sí queremos hacer notar que en esta fecha tan temprana - 1206- era muy poco frecuente el uso del castellano y menos aún para redactar un privilegio rodado, último tipo documental - como se verá más adelante- en incorporar la lengua vulgar a su forma de emisión.

Los otros dos documentos seleccionados por Lomax ciertamente no son originales, pues - se ha señalado ya - el de 1210 se conserva dentro una confirmación de $1282^{23}$ y el de 1213 es considerado por su editor como copia figurada de la época ${ }^{24}$. Sin embargo —desde nuestro punto de vista-podrian ser tomados en consideración para conocer la realidad de la introducción del castellano en la cancillería real. En primer lugar, porque sus contenidos y el uso preciso de ambas lenguas -en función de unas partes concretas de los mismos-van a coincidir con la realidad detectada en el reinado de Fernando III. Son dos privilegios rodados, cuyas fórmulas iniciales y finales vienen escritas en latín y el texto en casteIlano. El primero se trata de una confirmación de términos entre Cuéllar y Aguilafuente; el segundo, de la ratificación de una pesquisa llevada a cabo para determinar el uso de un monte. Tanto la fijación de los términos como el resultado de la pesquisa han hecho uso del romance, entendemos que para una mayor claridad y más fácil comprensión. En segundo lugar, porque la notificación universal, la intitulación individual o conjunta del monarca, el dispositivo, la cláusula de sanción, la expresión de la fecha, las columnas de confirmantes y la completa línea de cancillería - todo ello en latín- se ajustan a las pautas y formas adoptadas en otros documentos coetáneos de Alfonso VIII.

Como se ha señalado, L. Rubio Garcia incorpora en su selección de documentos de Alfonso VIII tres que se conservan copiados en tumbos o cartularios. Uno, que es de fecha muy temprana -1194- se encuentra en el Tumbo B de Santiago ${ }^{25}$ y recoge la pesquisa sobre términos en una zona fronteriza entre las provincias de Palencia y de León. Más concretamente, a causa de un pleito entre el lugar de Ledigos, que pertenecía a la iglesia compostelana, con la villa palentina

19 Vid. J. Gonzalez, Op. cit., doc. 845.

20 Ibidem, doc. 1005.

21 Vid. J. M. a Fernandez Catón, Colección documental de la catedral de León, VI (1188-1230), doc. 1867.

22 Ibidem, p. 167

23 Vid. J. Gonzalez, Op. cit, doc. 1031

24 Vid. J. Gonzalez, Op. cit., doc. 905.

25 Vid. J. Gonzalez, Op. cit., doc.632. 
de Saldaña. Para la resolución del conflicto se acudió al monarca castellano a pesar de que se trataba de un lugar dependiente del poderoso arzobispado santiagués. En la data -incompleta- se incorporan los nombres de los obispos de León y de Palencia junto con el abad de Sahagún, algo inusual por dos cuestiones. La primera, porque no era habitual añadir prelado alguno en la data histórica, en la que también se mencionan los nombres del rey -Alfonso VIII- y de su mujer - Leonor-; la segunda, porque el obispo de León y el abad de Sahagún formaban parte del reino leonés. Desde la notificación, con una forma de expresión que más adelante estará presente en la documentación hasta casi finales del s. XIII - Conosçuda cosa sea a todos los omnes que sean et a todos que serán-, hasta la sanción, data histórica y la expresión de la era han sido redactadas en castellano. En latín, la común invocación al nombre de Dios, la breve confirmación del monarca - modo de validación incluido-, el mes de la fecha, el escriba que lo materializó - Petrus scripsit- y la leyenda de la rueda. No han sido copiados en el cartulario la lista de los confirmantes, pero resulta extraño que se haya transcrito la suscripción del autor material antes del signo real sin mencionar, por otra parte, la iussio del canciller real -Didacus Garsie ${ }^{26}$ - , que en aquella época era normal.

El segundo de los documentos conservados en un códice diplomático y tenido en consideración por L. Rubio Garcia, se localiza en el llamado Tumbo Menor de Castilla ${ }^{27}$ y está íntegramente en castellano. Aparecen redactados en latín, tan sólo las tres palabras del inicio - Hec est memoria- y quizás también la fecha se pueda incluir, ya que expresa únicamente el año en números romanos precedidos de era. Su contenido es la narración del compromiso por parte de Pedro Fernández de entregar el castillo de Santa María de Albarracin a la orden de Santiago. En el texto se señala que el acuerdo se hizo en presencia de Alfonso VIll y del maestre $\mathrm{Pe}$ dro Arias, pero ello no implica necesariamente que este documento hubiera sido expedido por la cancillería de este rey y, por tanto, quizás no sea prudente considerarlo como tal, a no ser que se pudieran examinar los caracteres externos en un original que al parecer no se conserva. Del mismo modo, dudamos de la incorporación de la pesquisa sobre heredades del prior de S. Juan de Burgos, de fecha incierta, pero en todo caso anterior al fallecimiento de Alfonso VIII, aunque se señale la iussio de este monarca ${ }^{28}$.

En el cartulario de Santa María del Puerto, en la provincia de Santander, se encuentra el tercer documento que recoge el citado L. Rubio García en su trabajo. Se trata, como en casos anteriores, de la orden del monarca castellano de efectuar una pesquisa en 1210 para aclarar las heredades que pertenecian a este monasterio $^{29}$. La información proporcionada por los encargados de llevar a cabo tal averiguación se hizo en el lenguaje plano y las fórmulas cancillerescas previas y posteriores en latín.

\footnotetext{
Diego Garcia fue canciller castellano desde 1192 hasta 1214.

Vid. J. González, Op. cit., doc. 889.

Via. R. Menendez Pidal, Op. cit., doc. 165

Ibidem, doc. 165.
} 
En último lugar, L. Rubio García selecciona otros dos privilegios rodados originales - de 1211 y 1214 -, que contienen el amojonamiento entre las villas de Escalona y Maqueda ${ }^{30}$ y una permuta protagonizada por los monasterios de Oña y S. Andrés del Arroyo ${ }^{31}$. No están intitulados por el rey, sino que su intervención aparece al final -antes de la data-confirmando ambos asuntos; en los dos se encuentra la iussio del canciller -Diego García-y del notario -Pedro PonceEsta parte final, claramente cancilleresca, está en el latín de la época y lo mismo se observa en el inicio. Los dos privilegios están redactados en una mezcla de romance y latín ${ }^{32}$.

Por consiguiente, con independencia de los numerosos vocablos romances que se intercalan en los documentos expedidos por la cancilleria de Alfonso VIII, al final de su reinado se pueden localizar los primeros que incluyen párrafos completos en castellano. Todos de inicios del siglo XIII, menos el que se copió en el Tumbo de Santiago de 1194. Todos relacionados con deslinde de términos, problemas de heredades o cambio de titularidad de éstas, a excepción del singular Tratado de Cabreros. Con las reservas de originalidad de alguno o de consideración de documento cancilleresco de otros, no hay lugar a dudas que la cancillería castellana de este monarca, además de las importantes novedades que incorporó - sello de plomo y rueda, entre otros-, no pudo sustraerse finalmente a lo que debía ser una realidad palpable y muy extendida en su época: la lengua romance que comprendian todos sus vasallos frente al latín de la Iglesia y de la cancillería, que cada vez entendían menos personas. Una situación que debió adelantarse en la documentación privada, menos encorsetada a unas normas tan precisas y -por su propia naturaleza - mucho más próxima a la población que, desde hacía tiempo, se había alejado y separado del lenguaje oficial.

II. Lo que ocurrió a partir de entonces no fue sino el progresivo aumento de presencia del castellano en los documentos reales. Un incremento que se puede apreciar en el reinado de Fernando III, primero rey de Castilla (1217-1230) y después también de León (1230-1252), dado que en los tres años que gobernó Enrique I en Castilla (1214-1217) sus documentos no muestran ninguna cláusula o fórmula redactada en lengua vulgar.

Para el análisis de la cancillería fernandina se cuenta, asimismo, con una colección diplomática de 852 piezas documentales publicadas por J. González ${ }^{33}$, que nos va a servir de base para proseguir con este análisis.

30 Vid. J. GonzÁLEZ, Op. cit., doc. 882.

31 Ibidem, doc. 925

32 Por otra parte, F. J. Hernández ha dado a conocer una copia de un cuaderno de unas Cortes de Toledo de 1207, que se conserva en el archivo de la catedral de esa ciudad, con medidas económicas sobre precios y productos del mercado, cuyo texto está en castellano, menos la intitulación, dirección y salutación. Al parecer esta copia se hizo en fecha muy próxima al original (vid. F. J. HERNANDEZ, "Las cortes de Toledo de 1207 ", en Las Cortes de Castilla y León en la Edad Media, Valladolid 1988, t. 1, pp. 221-253).

33 Vid. J. Gonzalez, Reinado y diplomas de Femando III, 3 t., Córdoba, 1980-1983. 
A la primera época del reinado de Fernando III, es decir, como sucesor de su abuelo materno en Castilla, corresponden doscientos setenta documentos, que se dividen casi mitad por mitad en originales - 129- y copias - 139-, muchas de ellas insertas en confirmaciones de su hijo Alfonso $X^{34}$. En veintisiete de ellos -el primero de 1219 - se ha utilizado el romance como medio de comunicación ${ }^{35}$, siendo considerados nueve como originales por su editor.

El más antiguo entre éstos data de 1223 y se trata de un mandato a todos los súbditos para que ante la necesidad de trasladar ganado y mercancías, lo hicieran por los puentes de Toledo, Alarilla y Zorita ${ }^{36}$. Su estructura presenta lo que va a constituir casi una norma en este tipo documental durante gran parte de su reinado. Nos referimos al uso del latín al principio y al final. Más concretamente, en la triple secuencia formulistica caracteristica de los mandatos -intitulación, dirección y salutación-y, asimismo, en la expresión de la fecha. Una data iniciada por facta carta e incluyendo la iussio regia merced a la expresión rege exprimente, que ya en el reinado anterior había sido incorporada en este lugar. La fórmula intitulativa se caracteriza, además, por estar iniciada directamente por el nombre del monarca, sin pronombre que preceda y sin aparecer acompañado por algún miembro de la familia real. Por contra, el contenido, generalmente expresado de manera muy sucinta e introducido o no por una escueta notificación - sepades-, se expresa en castellano, inclusive la cláusula de sanción material que llevan algunos ${ }^{37}$.

A esta común realidad de los mandatos fernandinos de esta primera época, hay que añadir un nuevo original de contenido similar a los anteriores, pero con una estructura diplomática diferente. Su cronología es de 1227 y está relacionado con el pago de pechos ${ }^{38}$. Totalmente en castellano, a excepción de la data, y con verbos expresados en pasado, carece de salutación, no comienza por el nombre real, sino por la notificación habitual en los otros tipos documentales. La ausencia de anuncio de validación en el texto y la carencia de datos descriptivos al respecto nos impiden determinar si se trata de una carta plomada o una carta abierta - en todo caso de inicio notificativo - algo que era usual para las concesiones, pero no así para los mandatos.

No sólo documentos de carácter iusivo se encuentran en romance en esta primera etapa, también en los documentos más solemnes de la cancilleria - los privilegios rodados- el castellano se abre paso en el tenor documental. Ahora bien, de momento para expresar cuestiones determinadas. El diploma con rueda y original más antiguo - según J. González - se remonta a 1225 y se trata de la con-

34 Vid. P. Ostos SALCEDO, "La cancilleria de Fernando III, ray de Castilla (1217-1230). Una aproximación. , en Fernando III y su época, (Sevilla, 1995), p. 60.

${ }_{35} \mathrm{Vid}$. J. Gonzal.EZ, Fernando III., docs. 55, 75, 86, 144, 148, 167, 174, 176, 180, 183, 190, 195, 206 $220.227,234,235.236,237,239,245,246,252,253,259,262$ у 263.

36 lbidem, doc. 183.

17 De igual fecha, idéntica estructura y modo de utilización de ambas lenguas es el mandato original de $D^{a}$ Berenguela, en el que se intitula reina de Castilla y de Toledo (en Ibidem, doc. 176).

38 Ibidem, doc. 227. 
firmación regia de un deslinde de términos entre Cuenca, Monteagudo y Paracuellos ${ }^{39}$. La notificación inicial y la determinación del contenido están en latín. A continuación, el deslinde viene expresado en vulgar. Retorna el latín para la intitulación amplia del rey, con la compañía de su mujer - Beatriz-y de sus tres hijos -Alfonso, Federico y Fernando-, para el beneplácito de $\mathrm{D}^{\mathrm{a}}$ Berenguela y para la disposición. En lengua clásica continúa el diploma para expresar la cláusula de sanción, la data y la completa validación que portan en general todos los privilegios rodados. Es, naturalmente, la naturaleza de su contenido lo que justifica el uso del romance.

Los restantes privilegios rodados de esta primera época fernandina con ciertas partes en romance son copias posteriore ${ }^{40}$ y muestran una realidad similar a la descrita con anterioridad, único original conservado. Es decir, utilización del vulgar para el desarrollo de sus contenidos y del latín para el resto. Pero su explicación radica, precisamente, en el carácter de estos asuntos, ya que se trata de fueros, de conflictos de términos o sobre heredades, que el monarca confirma tras una averiguación judicial previa.

A esta doble realidad señalada de uso de ambas lenguas en función del tipo documental por una parte y por otra del carácter del contenido, hay que añadir la presencia de suscripciones confirmativas del monarca en ciertos documentos - con aposición del sello como medio de validación ${ }^{41}$ - hechas en castellano pero con alguna que otra palabra en latín: ego o mea mater.

Pero ya se empieza a detectar una situación que va a ser frecuente en las dos décadas siguientes, aunque para esta etapa exclusivamente castellana sólo se conozca a través de una confirmación de su nieto Sancho IV ${ }^{42}$, consistente en la aprobación de Fernando III del acuerdo en un litigio acerca de unas heredades. Nos referimos a una redacción íntegra en castellano, con la salvedad de la data y de la línea de cancillería - lohannes de Aça, iussu cancellarii, scripsit-. El inicio de este documento es notificativo - Sabuda cosa sea a todos los que esta carta uieren et oyeren - y fue validado con el sello pendiente. Desconocemos no obstante si la materia del mismo era plomo o cera, aunque es posible que se tratara de lo primero, que imprimía a los documentos un efecto más perdurable. Sí esto fuera cierto, sería la primera carta plomada notificativa redactada casi completamente en romance, inclusive la intervención del rey y la cláusula de sanción.

Así, en estos primeros años de reinado fernandino, el uso de la lengua materna se va haciendo cada vez más visible en la cancillería castellana, pero continúa siendo minoritaria frente al tradicional latín, ya que no supone más de un $10 \%$ de la documentación conservada. Por otra parte, no hay duda en afirmar que su empleo está relacionado con ciertos contenidos y es mucho más frecuente en documentos

39 Ibidem, doc. 206.

4) Ibidem, docs. 55, 75, 86, 144, 148, 167 y 195

a) Ibidem, doc. 237.

42. Ibidem, doc 259 
de carácter iusivo que en otros de concesión o confirmación, pues la utilización en éstos se limita exclusivamente al desarrollo de la justificación que precisaba o demandaba la ratificación regia.

III. Mediado el mes de septiembre de 1230, Fernando III obtiene la corona del reino de León a raíz del fallecimiento de su padre Alfonso IX. La unión territorial y politica de ambos reinos se verá aún más engrandecida con las significativas incorporaciones de extensas e importantes zonas del sur de la Península, que en pocos años se fueron integrando al dominio castellano-leonés y dejando atrás su amplio periodo de dominio musulmán. Nos referimos a las conquistas del valle del Guadalquivir, con Córdoba y Sevilla como ciudades más emblemáticas.

La actividad de la cancillería real se incrementó de manera muy notable, pues se procedió a confirmar muchas de las mercedes otorgadas por el anterior monarca leonés por una parte y por otra, se hizo necesario reorganizar los nuevos territorios incorporados, establecer las normas por las que debian regirse y, asimismo, recompensar las ayudas o méritos prestados, en especial por nobles, caballeros $u$ órdenes militares. Quinientos ochenta y dos documentos de los publicados por J. González corresponden a estos veintidós últimos años del reinado de Fernando III. Lo primero que se observa es un aumento considerable del romance en su documentación si se compara con la época anterior, ya que de esos casi seiscientos documentos, ciento noventa y ocho han sido redactados en parte o casi en su totalidad en lengua castellana. De éstos, setenta y tres corresponden a la década de los 30 y los ciento veinticinco restantes fueron realizados entre 1241 y 1252 . Por tanto, de un $10 \%$ se pasa a un $34 \%$, siendo mayor la proporción a partir de $1240^{43}$. Además de que el avance del romance fue siempre un proceso paulatino, hay que tener en cuenta que en un principio muchos documentos expedidos por la cancillería iban dirigidos al reino de León -en ese proceso de confirmación de mercedes que prosigue a un nuevo reinado- y para ellos se utilizó preferentemente el latín.

IV. En el periodo comprendido entre 1230 y 1240 , son treinta y uno los que han llegado hasta nosotros en su forma primigenia ${ }^{44}$. Atendiendo a su contenido, algo más de la mitad curresponden a órdenes del monarca, es decir, hay treinta y ocho documentos de carácter iusivo, que muestran al principio la misma realidad que en la etapa anterior, es decir, la triple secuencia formulística inicial y la data que los cierra en latín. Sin embargo esta situación va a ir cambiando con el transcurso de los años y ya en diversas ocasiones el uso de la lengua tradicional se limita a la intitulación y a la data ${ }^{45}$.

43 El número de documentos originales es también mayor por lo que el análisis del proceso se hace más fiable.

44 Ibidem, docs. 283, 305, 325, 334, 340, 356, 378, 478, 504, 506, 515, 516, 519, 520, 526, 534, 563, $591,594,595,600,617,622,629,631,638,644,648,649,658$ у 662

45 Ibidem, docs. 568 y 596, de 1236 y 1237 respectivamente. 
Al igual que la situación mostrada con anterioridad, los ocho privilegios rodados ${ }^{46}$ que presentan romance están relacionados con deslinde de términos, pleitos o resultados de pesquisas, que Fernando III confirma a través de este tipo documental y valida con su sello de plomo y con la prolija relación de confirmantes. En ellos, el castellano se sigue empleando para la redacción precisa de unos términos en conflicto, en el desarrollo de pleitos o en la investigación originada por unos litigios surgidos al albur de intereses cruzados en la propiedad de heredades o lugares colindantes.

Una nueva situación se añade en esta década y es que el avance del castellano va a alcanzar también a la ratificación real, por lo que el uso del latín queda reducido a la invocación verbal - cuando se emplea- y a la expresión de la data. Esto se aprecia en una tipología diferente a la ya reseñada, es decir, en cartas plomadas y abiertas - ambas notificativas - y, asimismo, para unos contenidos cada vez más variados y diversos. En efecto, aunque persiste la temática anterior de deslindes de términos o de indole judicial ${ }^{47}$, ésta no va a ser la única ya que se aprecia ahora para concesiones o donaciones regias de diversa naturaleza. Así -1234 - Fernando III autoriza una venta de bienes y lo hace en un breve documento en castellano, que comienza por la notificación de la época y acaba con una data en latín. Un año más tarde, varias donaciones de heredades en el término de Úbeda (Jaén) muestran la misma realidad ${ }^{48}$ y lo mismo ocurre al final de esta década cuando dona unas propiedades en Córdoba ${ }^{49} \mathrm{o}$ aprueba una permuta de bienes a instancias de su canciller D. Juan ${ }^{50}$.

Es un hecho cierto, por tanto, que el uso del romance traspasa ya las fronteras de unos contenidos determinados y es utilizado cada vez con mayor asiduidad y de manera más amplia. Sólo la expresión de la fecha de estos documentos persiste en su desarrollo en latín y parece ser la fórmula más reticente al cambio de lengua ${ }^{51}$ junto con la invocación, que en ocasiones perdurará más tiempo aún, si bien hay que tener en cuenta que su presencia en la documentación real castellana no es siempre constante por una parte y por otra parte, que al tratarse de una apelación a la divinidad es más lógico que se acuda a la lengua oficial de la iglesia para su forma de expresión.

V. En 1242, aparece por vez primera la mención de los dias en castellano ${ }^{52}$, pero constituye una excepción. Ahora bien, en 1243 un privilegio rodado que contiene un cambio de heredades con el arzobispo de Toledo prolonga el romance hasta la suscripción real ${ }^{53}$, algo hasta entonces inusual para este tipo documental,

46 Ibidem, docs. $325,340,506,507,519,520,629$ y 649

1) Ibidem, docs. 305,458 y 507

${ }^{48}$ Ibidem, docs. 559,561 y 562

49 Ibidem, doc. 638 .

so Ibidem, doc 658

51 Hemos detectado cinco documentos de la época siguiente, entre 1242 y 1252 , con la fecha también en castellano, pero son copias posteriores (Ibidem, docs. 704, 776, 786 y 846 )

52 Ibidem, doc. 689

53 Ibidem, doc. 710 . 
ya que la realidad más generalizada — se ha señalado ya - consistía en el uso del latín tanto en las fórmulas iniciales como en la parte final que abarcaba la sanción, corroboración regia, data y validación. No obstante, es un hecho que a partir de 1243 el castellano continuó avanzando en su conquista, incluso en el documento más solemne de la cancillería, ya que cada vez se hizo más frecuente que el latín apareciera sólo a partir de la fecha. Es decir, se observa ya en los privilegios rodados idéntica presencia de una lengua $u$ otra que en el resto de la tipología documental emitida por esta oficina de expedición regia y que se detectaba en la década anterior. No se da, por consiguiente, a partir de ahora una diferenciación lingüistica en función de la solemnidad o no de los documentos y ello puede ser considerado como el predominio indiscutible de la lengua castellana frente a la clásica y tradicional. Esta situación va a permanecer hasta el final del reinado de Fernando III.

Es digno de resaltar el caso de Córdoba, que en 1241 y en el plazo de un mes recibió dos documentos de singular trascendencia para la ciudad. Nos referimos al fuero o norma que debía observar esta ciudad para su buen regimiento: primero en romance ${ }^{54}$ y después en latín ${ }^{55}$, con escasas variaciones en su contenido. El segundo es un privilegio rodado y el primero parece tratarse de una carta plomada, ya que carece de rueda y de confirmantes. Éste se inicia en latín con una invocación al nombre de Dios y de los santos Pedro y Pablo, en cuyo día se conquistó la ciudad en 1236; prosigue con la intitulación de Fernando III y una breve exposición en la que se señala que el fuero se promulga en vulgar para que no hubiera dudas acerca de sus disposiciones: et ut presentibus et futuris que donanda decreuimus clarius elucescant non ea in latino set in uulgari idiomate promulgamus; más adelante, se añade que el Libro ludgo que les yo do, que ge lo mandaré trasladar en romanz e que sea llamado fuero de Córdoba. Pareciera que recogida la norma en castellano en la propia ciudad de Córdoba para que fuera entendida por todos e intentar evitar problemas o errores en su aplicación, un mes después la cancillería le expidiera otro - desde Toledo-- con todas las solemnidades requeridas para un contenido de estas características, integramente en latín y, según indica la descripción recogida en un Tumbo del siglo XIV, validado - al parecer- con un sello de plata ${ }^{56}$.

En este segundo caso, es evidente que la importancia del contenido explica el tipo documental adoptado y la lengua empleada. Ahora bien también se justíica por la cronología en que fue emitido, porque cinco años más tarde -1246-, el fuero que el monarca dio a la ciudad de Cartagena, -también un privilegio rodado-, hace uso del castellano hasta la fecha que es cuando se da el cambio de lengua ${ }^{57}$, como ocurría ya con otros muchos de contenidos muy diversos.

\footnotetext{
lbidem, doc. 670 .

Ibidem, doc. 677

Ibidem, doc. 670

lbidem, doc. 733 .
} 
VI. El análisis de estos documentos, en especial de los originales, permite determinar, por consiguiente, que los primeros indicios claros de romance en la documentación emitida por la cancillería castellana se ha de situar en la última época del reinado de Alfonso VIII, coincidiendo con el final del siglo x\|l y los primeros años de la centuria siguiente. Un periodo que se caracteriza, según $M$. Pérez González, por un fenómeno claro de bilingüismo y en el que se hace innegable la contaminación del romance sobre el latín ${ }^{58}$.

En el reinado de Fernando III, aunque son más numerosos los documentos en latín, el paulatino avance del castellano en su cancillería es una realidad incontestable, en especial desde 1230.

Esta situación es muy similar a la mostrada por los documentos no reales que se conservan en los archivos de la catedral de León y del monasterio de Sahagún. En el primero, la realidad documental testimonia que el uso del romance se hizo común y corriente en la década de 1240. Más concretamente, J. M. Ruiz Asencio determina que si el predominio del latín es incontestable entre 1230 y 1240 , la situación cambió totalmente a partir de 1250, época en la que el uso de esta tradicional lengua quedó casi reducido a contenidos de carácter eclesiástico ${ }^{59}$. A su vez, J. A. Fernández Flórez concluye que también la década de 1240 constituye el punto de inflexión de este cambio en la documentación del importante monasterio benedictino de Sahagún, siendo abrumador el uso del romance en la segunda mitad del siglo $\mathrm{XIII}^{60}$. Del mismo modo, $\mathrm{C}$. Hernández pone de manifiesto que el predominio del vulgar en textos palentinos comenzó a darse a partir de $1222{ }^{61}$. Esta evolución ya sin retorno, es decir, el triunfo del romance debió suponer una liberación para los notarios, ya que sus conocimientos de latín eran cada vez más es$\operatorname{casos}^{62}$.

Hace años, R. Menéndez Pidal fijaba la extensión del vulgar con la expansión territorial que supusieron las conquistas fernandinas, primero en el ámbito notarial y después en el real, reservándose el latín para los privilegios más solemnes. Circunstancia ésta que consideraba como factor de suma importancia en la difusión y desarrollo del castellano ${ }^{53}$.

58 Vid. M. Perez Gonzalez, Op. cit., p. 255.

59 En concreto, señala que entre 1230 y 1240 hay 33 documentos en latín y 8 en romance; en la década siguiente, hay 28 en latin y 31 en romance; entre 1251 y 1260 , los latinos son 16 frente a 53 en vulgar; y de 1261 a 1264 , solo hay 7 en latin y 30 en romance (Vid. J. M. RuIz AsEncio, Colección documental del Archivo de la Catedral de León, VIII (1230-1269), León, 1993, p. XXXVII).

60 Indica J. A. Fernández Flórez que entre 1200 y 1240, la presencia del romance es muy esporádico. pues se conservan 21 documentos frente a 139 en latin; en la década 1241-1250, la realidad empieza a cambiar, pues hay 17 en el primero y 3 en el segundo; de 1251 a 1300, los castellanos son 168 y los latinos nada más que 21 ( Vid. J. A. Fernandez Florez, Colección diplomática del monasterio de Sahagún, $V(1200-1300)$, León, 1994, p. XIX).

${ }_{61}$ Vid. C. HeRnÁNDEZ, "Acercamiento al castellano del s. XIII", en Scripta Philologica. In honorem Juan M. Lope Blanch, México 1992, pp. 329-344.

6? Vid. J. A. Frago GaRCiA, «El paso del romance a la escritura: problemas culturales y lingüisticos", en 24 Semana de Estudios Medievales, Estella 1997, pp. 89-93.

63 Vid. R. Menendez Pidal, Op. cit., p. 12. 
Esa cadena de romanización que A. Emiliano proponía para la lengua notarial se observa también sin interrupción alguna en la documentación cancilleresca. Se pasa de unas primeras palabras en romance para reflejar topónimos u onomástica hasta la redacción integra - o casi- en castellano de los documentos en las dos últimas décadas de la primera mitad del siglo xill. Una evolución que se observa con nitidez y que permite destacar su empleo primero para textos relacionados con problemas de términos y de propiedades o bien para expresar con claridad las órdenes emitidas por el rey ${ }^{64}$.

Diplomáticamente hablando, se aprecia, asimismo, que su utilización en cancillería está relacionada con los mandatos primero y después, con aquellas cartas - abiertas o plomadas notificativas - en las que el monarca concedía o confirmaba alguna actuación privada. Fue el privilegio rodado el último en redactarse en lengua vulgar, con la excepción de los que incorporaban en su texto alguna pesquisa o fallo judicial. Quizá durante un cierto tiempo, la solemnidad que este tipo documental conllevaba venia arropada con esa lengua tradicional en la que se expresaba todo su amplio ropaje formulístico. Sin embargo, esta dualidad lingüística no pudo resistir durante mucho tiempo el fuerte empuje del castellano y al final del reinado de Fernando III muchos privilegios rodados también fueron escritos casi íntegramente en vulgar. Sólo la data en todos los tipos documentales y la validación en éste último se resistieron a ser expresadas en plano lenguaje. Pero esta situación duró muy poco tiempo, ya que el reinado de Alfonso $X$ supuso - como se sabe- el triunfo definitivo del romance en la documentación real y notarial ${ }^{65}$ e hizo, además, de la lengua hablada una prosa literaria escrita ${ }^{66}$. Alfonso $X$, consciente de que el castellano era la lengua de sus súbditos, hizo trasladar a ésta casi toda su gran labor cultural y científica con la clara intención - manifestada en el prólogo de su Lapidario - de facilitar su comprensión y procurar su mayor aprovechamiento ${ }^{67}$.

64 Según J. A. Frago Garcia, ios documentos relacionados con judios solian estar en castellano (lbidem, p. 92).

${ }_{65.5}$ Cuestión bien diferente es la existencia o no de una disposición regia decretando que todos los documentos de la cancillería deberian ser redactados a partir de entonces en castellano, que unos sitúan en tiempos de Fernando III (Vid. A. Alonso, Castellano, español, idioma nacional, Buenos Aires, 1968, p. 60.- W. BAHNER, La lingüistica española del siglo oro, Madrid, 1966, p. 29) y otros con Alfonso $X$ (Vid. E. S. Procter, The Castilian Chancery during the reign of Alfonso X. 1252-1284, Oxford, 1984, pp. 105106.- D.W. Lomax, Op. cit, pp. 415-416), en unas supuestas cortes de 1253 (Vid. O. Nandris, “Le latin, la romanisation et le castillan», REL, 1967, 45, pp. 77-82), y otros rechazan (VId. F. GONZALEZ OLLÉ, «E) establecimiento del castellano como lengua oficial», en BRAE, LXIII, 1978, pp. 231-232). Pocos indicios hay de esa norma general, aunque no existe duda alguna del interés expreso de Alfonso $X$ de trasladar textos literarios y cientificos de otras lenguas al castellano para que los hombres io entendiesen mejor $y$ se supiesen de él mas aprovechar ("Lapidario") o como se dic en un documento anterior emitido en latín para que la parte implicada las pudiesse entender, mandelas tornar en romanz (Vid. J. A. FERNANDEZ FLOREZ, Op. cit., doc 1722). Es cierto, por otra parte, que entre los requisitos exigidos al Canciller, las Partidas establecian que debia saber leer ef escribir también en latín como en romance (Vid. Partidas II. IX, IV).

a) Vid. A. Galmes de Fuentes, "Alfonso X el Sabio y la creación de la prosa literaria castellana", en Estudios Alfonsies, Granada 1985, p. 35.

ti Vid. J. ValdEON, Alfonso X el Sabio. La forja de la España Moderna, Madrid, 2003, pp. 171-172. 